\title{
Maternity Care Practices and Breastfeeding Among Adolescent Mothers Aged 12-19 Years — United States, 2009-2011
}

\author{
Oluwatosin Olaiya, $\mathrm{MBChB}^{1,2}$; Deborah L. Dee, $\mathrm{PhD}^{2}$; Andrea J. Sharma, $\mathrm{PhD}^{2}$; Ruben A. Smith, $\mathrm{PhD}^{2}$
}

The American Academy of Pediatrics recommends that infants be breastfed exclusively* for the first 6 months of life, and that mothers continue breastfeeding for at least 1 year (1). However, in 2011 , only $19.3 \%$ of mothers aged $\leq 20$ years in the United States exclusively breastfed their infants at 3 months, compared with $36.4 \%$ of women aged $20-29$ years and $45.0 \%$ of women aged $\geq 30$ years. ${ }^{\dagger}$ Hospitals play an essential role in providing care that helps mothers establish and continue breastfeeding. The U.S. Surgeon General and numerous health professional organizations recommend providing care aligned with the Baby-Friendly Hospital Initiative (BFHI), including adherence to the Ten Steps to Successful Breastfeeding (Ten Steps), as well as not providing gift packs containing infant formula $(2,3)$. Implementing BFHIaligned maternity care improves duration of any and exclusive breastfeeding among mothers $(4,5)$; however, studies have not examined associations between BFHI-aligned maternity care and breastfeeding outcomes solely among adolescent mothers (for this report, adolescents refers to persons aged 12-19 years). Therefore, CDC analyzed 2009-2011 Pregnancy Risk Assessment Monitoring System (PRAMS) data and determined that among adolescent mothers who initiated breastfeeding, self-reported prevalence of experiencing any of the nine selected BFHI-aligned maternity care practices included in the PRAMS survey ranged from $29.2 \%$ to $95.4 \%$. Among the five practices identified to be significantly associated with breastfeeding outcomes in this study, the more practices a mother experienced, the more likely she was to be breastfeeding (any amount or exclusively) at 4 weeks and 8 weeks postpartum. Given the substantial health advantages conferred to mothers and children through breastfeeding, and the

\footnotetext{
*Exclusive breastfeeding means that the infant receives only breast milk. No other liquids or solids are given (not even water) with the exception of oral rehydration solution, or drops/syrups of vitamins, minerals, or medicines (http:// www.who.int/elena/titles/exclusive_breastfeeding).

$\dagger$ http://www.cdc.gov/breastfeeding/data/nis_data/rates-any-exclusive-bf-sociodem-2011.htm.
}

particular vulnerability of adolescent mothers to lower breastfeeding rates, it is important for hospitals to provide evidence-based maternity practices related to breastfeeding as part of their routine care to all mothers, including adolescent mothers.

PRAMS is a surveillance project that collects state-specific, population-based data on maternal attitudes and experiences before, during, and after pregnancy among women with a recent live birth. ${ }^{\S}$ Because PRAMS surveys are completed by mothers at approximately $2-9$ months postpartum,,$\$$ CDC categorized the duration of any and exclusive breastfeeding as $\geq 4$ weeks and $\geq 8$ weeks to ensure that all respondents had an equal opportunity to be included in the analysis. CDC used 2009-2011 PRAMS data (the most current data available) from New York City and

$\overline{\$}$ http://www.cdc.gov/prams/methodology.htm.

\section{INSIDE}

23 Increasing Prevalence of Gastroschisis - 14 States, 1995-2012

27 Inadequate Diagnosis and Treatment of Malaria Among Travelers Returning from Africa During the Ebola Epidemic — United States, 2014-2015

30 Interim Guidelines for Pregnant Women During a Zika Virus Outbreak — United States, 2016

34 Notes from the Field: Outbreak of Locally Acquired Cases of Dengue Fever — Hawaii, 2015

36 Notes from the Field: Tetanus Cases After Voluntary Medical Male Circumcision for HIV Prevention Eastern and Southern Africa, 2012-2015

38 QuickStats

Continuing Education examination available at http://www.cdc.gov/mmwr/cme/conted_info.html\#weekly.

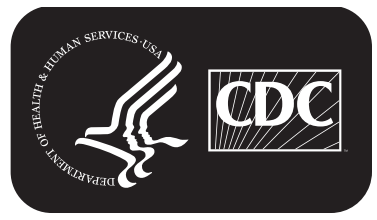

U.S. Department of Health and Human Services Centers for Disease Control and Prevention 
10 states that included the maternity practices module during at least 1 study year and met the $65 \%$ response rate threshold. The module assessed breastfeeding-related maternity care mothers experienced during the delivery hospitalization. Only mothers who had a hospital birth, initiated breastfeeding, and lived with their infant at the time of the survey completed the maternity practices module. CDC analyzed nine questions that assess breastfeeding-supportive (BFHI-aligned) maternity practices; eight correspond to the Ten Steps and one assesses distribution of hospital gift packs containing formula (Table 1). Adolescent mothers with infants who were full-term ( $\geq 37$ weeks), weighed $\geq 2,500 \mathrm{~g}$ at birth, and were never admitted to the neonatal intensive care unit were included in the analysis. Mothers with missing data on maternity practice questions, breastfeeding variables, or covariates (age, race/ethnicity, and Special Supplemental Nutrition Program for Women, Infants and Children [WIC] participation) $(\mathrm{n}=126)$ were excluded. The final sample size included 1,325 adolescent mothers, weighted to represent 104,030 adolescent mothers.

CDC estimated the prevalence of any and exclusive** breastfeeding for $\geq 4$ weeks and $\geq 8$ weeks. Of the nine BFHI-aligned

\footnotetext{
I Alaska, Arkansas, Colorado, Maine, Minnesota, New Jersey, New York, Oregon, Texas, Vermont.

** Breastfeeding exclusivity was derived from the PRAMS question "How old was your new baby the first time he or she drank liquids other than breast milk (such as formula, water, juice, tea, or cow's milk)?," to which mothers could answer in weeks or months, e.g., "my baby was less than 1 week old" or "my baby has not had any liquids other breast milk." Breastfeeding duration was derived from the PRAMS question, "How many weeks or months did you breastfeed or pump milk to feed your baby?" Mothers could answer in the number of weeks or months, or could respond that she breastfed or pumped milk for her infant for less than 1 week.
}

maternity practices adolescent mothers experienced, five were significantly associated with breastfeeding outcomes. For those five significantly associated practices (significant practices), CDC calculated adjusted prevalence ratios and 95\% confidence intervals (CIs) by using predicted marginal proportions from logistic regression models $(\sigma)$ to assess the association between the number of maternity practices experienced and any or exclusive breastfeeding at 4 and 8 weeks postpartum. CDC also assessed the dose-response relationship between the total number of these five significant practices that mothers experienced and breastfeeding prevalence. All regression models controlled for covariates. Statistical significance was defined as $\mathrm{p}<0.05$.

Among this sample of adolescent mothers who initiated breastfeeding, 64.4\% (95\% CI: 59.5-69.1) reported any breastfeeding for $\geq 4$ weeks and $40.9 \%$ (95\% CI: $36.2-45.7$ ) reported exclusively breastfeeding $\geq 4$ weeks. The prevalence of any and of exclusive breastfeeding for $\geq 8$ weeks declined to 44.6\% (95\% CI: 39.7-49.5) and 30.9\% (95\% CI: 26.6-35.6), respectively. The prevalence of BFHI-aligned maternity practices experienced during the delivery hospitalization varied across the nine selected practices: $95.4 \%$ of adolescent mothers received information about breastfeeding, whereas only $29.2 \%$ reported they did not receive a gift pack that contained infant formula (Table 2). Only four maternity practices (receiving information about breastfeeding, receiving assistance with breastfeeding, newborn staying in the same hospital room as the mother, and receiving a phone number to call for breastfeeding help after hospital discharge) were experienced by more than

The MMWR series of publications is published by the Center for Surveillance, Epidemiology, and Laboratory Services, Centers for Disease Control and Prevention (CDC), U.S. Department of Health and Human Services, Atlanta, GA 30329-4027.

Suggested citation: [Author names; first three, then et al., if more than six.] [Report title]. MMWR Morb Mortal Wkly Rep 2016;65:[inclusive page numbers].

\author{
Centers for Disease Control and Prevention \\ Thomas R. Frieden, MD, MPH, Director \\ Harold W. Jaffe, MD, MA, Associate Director for Science \\ Joanne Cono, MD, ScM, Director, Office of Science Quality \\ Chesley L. Richards, MD, MPH, Deputy Director for Public Health Scientific Services \\ Michael F. Iademarco, MD, MPH, Director, Center for Surveillance, Epidemiology, and Laboratory Services
}

MMWR Editorial and Production Staff (Weekly)

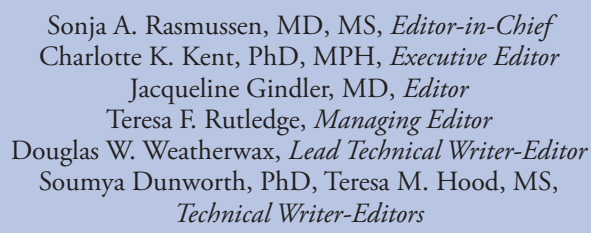

Sonja A. Rasmussen, MD, MS, Editor-in-Chief

Charlotte K. Kent, PhD, MPH, Executive Editor

Jacqueline Gindler, MD, Editor

Teresa F. Rutledge, Managing Editor

Douglas W. Weatherwax, Lead Technical Writer-Editor

Soumya Dunworth, PhD, Teresa M. Hood, MS, Technical Writer-Editors

\section{MMWR Editorial Board}

Timothy F. Jones, MD, Chairman

Matthew L. Boulton, MD, MPH

Virginia A. Caine, MD

Katherine Lyon Daniel, PhD

Jonathan E. Fielding, MD, MPH, MBA

David W. Fleming, MD

\author{
William E. Halperin, MD, DrPH, MPH \\ King K. Holmes, MD, PhD \\ Robin Ikeda, MD, MPH \\ Rima F. Khabbaz, MD \\ Phyllis Meadows, PhD, MSN, RN \\ Jewel Mullen, MD, MPH, MPA
}

Martha F. Boyd, Lead Visual Information Specialist

Maureen A. Leahy, Julia C. Martinroe,

Stephen R. Spriggs, Moua Yang, Tong Yang, Visual Information Specialists

Quang M. Doan, MBA, Phyllis H. King,

Teresa C. Moreland, Terraye M. Starr,

Information Technology Specialists

(1) 
$80 \%$ of adolescent mothers; however, none of these practices were associated with study outcomes. Feeding only breast milk at the hospital and breastfeeding in the first hour after the baby was born were the two maternity practices significantly associated with all breastfeeding outcomes (any and exclusive breastfeeding at both 4 and 8 weeks) (Table 2).

Only $7 \%$ of adolescent mothers reported experiencing all five of the practices significantly associated with any of the

TABLE 1. Correspondence of the Ten Steps to Successful Breastfeeding and indicators from the Pregnancy Risk Assessment Monitoring System maternity care practices module, 2009-2011

\begin{tabular}{lc}
\hline WHO/UNICEF Ten Steps to & $\begin{array}{c}\text { Corresponding indicator } \\
\text { from PRAMS maternity } \\
\text { puccessful Breastfeeding }\end{array}$ \\
\hline
\end{tabular}

1. Have a written breastfeeding policy

that is routinely communicated to

all health care staff.

2. Train all health care staff in skills necessary to implement this policy.

3. Inform all pregnant women about the benefits and management of breastfeeding.

4. Help mothers initiate breastfeeding within one hour of birth.

5. Show mothers how to breastfeed and how to maintain lactation, even if they are separated from their infants.

6. Give newborn infants no food or drink other than breast milk, unless medically indicated.

7. Practice "rooming in"—allow mothers and infants to remain together 24 hours a day.

8. Encourage breastfeeding on demand.

9. Give no pacifiers or artificial nipples to breastfeeding infants.

10. Foster the establishment of breastfeeding support groups and refer mothers to them on discharge from the hospital or clinic.
Hospital staff gave me breastfeeding.

I breastfed in the first hour after my baby was born.

Hospital staff helped me learn how to breastfeed.

My baby was fed only breast milk at the hospital. My baby stayed with me in
the same room at the hospital.

Hospital staff told me to breastfeed whenever my baby wanted.

My baby used a pacifier in the hospital.

The hospital gave me a telephone number to call for help with breastfeeding.

The hospital gave me a gift pack with formula information about

Abbreviations: PRAMS = Pregnancy Risk Assessment Monitoring System; UNICEF $=$ United Nations Children's Fund; $W H O=$ World Health Organization. * Adapted from the WHO/UNICEF version by Baby-Friendly USA to reflect the U.S. context (http://www.babyfriendlyusa.org/about-us/baby-friendlyhospital-initiative/the-ten-steps).

${ }^{\dagger}$ Although not included as one of the WHO/UNICEF Ten Steps, the PRAMS indicator "The hospital gave me a gift pack with formula," was included, as this is a practice that is detrimental to breastfeeding (http://www.surgeongeneral. gov/library/calls/breastfeeding).

breastfeeding outcomes (breastfeeding in the first hour after delivery, feeding the infant only breast milk at the hospital, hospital staff encouragement to breastfeed the infant on demand, not using a pacifier in the hospital, and not receiving a hospital gift pack that contained formula); 9.6\% reported not experiencing any of the five practices (Table 3 ). There was a significant dose-response relationship between the number of practices experienced and any or exclusive breastfeeding for $\geq 4$ weeks and $\geq 8$ weeks. The association between the number of maternity practices experienced and the prevalence of exclusive breastfeeding for $\geq 8$ weeks was statistically significant only among adolescent mothers who reported experiencing all five practices.

\section{Discussion}

Breast milk is the recommended source of optimal nutrition for most ${ }^{\dagger \dagger}$ infants. Although the maternal and child health advantages associated with longer duration of any and exclusive breastfeeding are well documented $(1,3,7)$, this study determined that among adolescent mothers who initiated breastfeeding, prevalence of any and exclusive breastfeeding was low. Specifically, the prevalence of any breastfeeding for $\geq 8$ weeks among adolescent mothers $(44.6 \%)$ was $40 \%$ lower than among PRAMS respondents aged $\geq 20$ years $(74.8 \%)$. The prevalence of exclusive breastfeeding for $\geq 8$ weeks among adolescent mothers (30.9\%) was approximately $25 \%$ lower than among PRAMS mothers aged $\geq 20$ years $(40.7 \%)$.

Maternity care practices a mother experiences during her intrapartum hospital stay can influence whether she chooses to initiate breastfeeding and how long she continues breastfeeding. The Ten Steps and the elimination of gift packs containing formula are elements of evidence-based maternity care that are associated with longer durations of any and exclusive breastfeeding (3). This study determined that among the five BFHI-aligned maternity practices with a significant independent association with breastfeeding, a positive doseresponse relationship exists between the number of practices experienced by adolescent mothers and their breastfeeding duration and exclusivity. However, many adolescent mothers who initiated breastfeeding were not provided this supportive care. Specifically, approximately half of adolescent mothers were exposed to fewer than three and $9.6 \%$ were not exposed to any of the five maternity practices associated with breastfeeding duration and exclusivity in this study.

Previous research indicates that the majority of adolescent mothers want to breastfeed their infants, and a substantial

\footnotetext{
$\dagger \dagger$ Few medical contraindications to breastfeeding have been described, such as untreated brucellosis in a mother and metabolic disorder of galactosemia in an infant (http://pediatrics.aappublications.org/content/129/3/e827.full).
} 
TABLE 2. Weighted prevalence of maternity care practices and adjusted prevalence ratios of any breastfeeding and exclusive breastfeeding ( $\geq 4$ weeks and $\geq 8$ weeks) by each maternity care practice experienced among adolescent* mothers -10 states ${ }^{\dagger}$ and New York City, Pregnancy Risk Assessment Monitoring System, 2009-2011

\begin{tabular}{|c|c|c|c|c|c|}
\hline \multirow[b]{3}{*}{ PRAMS module maternity practice $^{\dagger}$} & \multirow{3}{*}{$\begin{array}{l}\text { Experienced } \\
\text { the practice } \\
\quad(\%)\end{array}$} & \multicolumn{4}{|c|}{ aPR $(95 \% \mathrm{Cl})^{\S}$} \\
\hline & & \multicolumn{2}{|c|}{ Any breastfeeding? } & \multicolumn{2}{|c|}{ Exclusive breastfeeding? } \\
\hline & & $\geq 4$ weeks & $\geq 8$ weeks & $\geq 4$ weeks & $\geq 8$ weeks \\
\hline Hospital staff gave me information about breastfeeding & 95.4 & $0.83(0.67-1.02)$ & $1.02(0.63-1.64)$ & $1.39(0.79-2.45)$ & $1.41(0.67-2.98)$ \\
\hline I breastfed in the first hour after my baby was born & 59.0 & $1.26(1.07-1.48)$ & $1.42(1.12-1.82)$ & $1.63(1.25-2.14)$ & $1.46(1.05-2.03)$ \\
\hline Hospital staff helped me learn how to breastfeed & 83.1 & $0.98(0.80-1.21)$ & $0.83(0.63-1.09)$ & $1.32(0.90-1.95)$ & $1.25(0.78-2.02)$ \\
\hline My baby was fed only breast milk at the hospital & 38.9 & $1.33(1.15-1.54)$ & $1.57(1.27-1.95)$ & $2.46(1.90-3.18)$ & $2.40(1.75-3.30)$ \\
\hline $\begin{array}{l}\text { My baby stayed with me in the same room at } \\
\text { the hospital }\end{array}$ & 91.3 & $1.00(0.77-1.29)$ & $0.96(0.65-1.41)$ & $1.41(0.82-2.45)$ & $1.15(0.63-2.11)$ \\
\hline $\begin{array}{l}\text { Hospital staff told me to breastfeed whenever my } \\
\text { baby wanted }\end{array}$ & 72.5 & $1.28(1.04-1.58)$ & $1.70(1.23-2.35)$ & $1.39(1.00-1.92)$ & $1.43(0.96-2.13)$ \\
\hline My baby did not use a pacifier in the hospital** & 36.1 & $1.19(1.03-1.37)$ & $1.32(1.06-1.63)$ & $1.00(0.79-1.26)$ & $0.94(0.70-1.25)$ \\
\hline $\begin{array}{l}\text { The hospital gave me a telephone number to call for } \\
\text { help with breastfeeding }\end{array}$ & 80.0 & $1.07(0.89-1.29)$ & $1.22(0.91-1.63)$ & $1.16(0.85-1.58)$ & $1.14(0.78-1.66)$ \\
\hline The hospital did not give me a gift pack with formula** & 29.2 & $1.16(1.00-1.34)$ & $1.23(0.99-1.53)$ & $1.42(1.13-1.79)$ & $1.31(0.97-1.77)$ \\
\hline \multicolumn{6}{|c|}{$\begin{array}{l}\text { Abbreviations: aPR = adjusted prevalence ratios; } \mathrm{Cl}=\text { confidence interval; PRAMS = Pregnancy Risk Assessment Monitoring System. } \\
\text { * For this report, adolescents are defined as persons aged } 12-19 \text { years. } \\
\text { † Alaska, Arkansas, Colorado, Maine, Minnesota, New Jersey, New York, Oregon, Texas, Vermont. } \\
\text { § Prevalence ratios adjusted for maternal age, race/ethnicity, and receipt of Women, Infants, and Children (WIC) services during pregnancy. } \\
\text { 9 Boldface indicates a statistically significant result. }\end{array}$} \\
\hline \multicolumn{6}{|c|}{$\begin{array}{l}\text { ** Negative responses to PRAMS questions "my baby used a pacifier in the hospital" and "the hospital gave me a gift pack with formula" is indicative of receiving } \\
\text { appropriate maternity practice supportive of breastfeeding, thus the results are representative of receiving the appropriate practice. }\end{array}$} \\
\hline
\end{tabular}

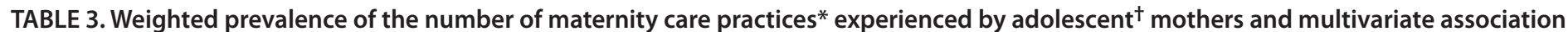
between the number of maternity care practice experienced and any breastfeeding and exclusive breastfeeding ( $\geq 4$ weeks and $\geq 8$ weeks) - 10 states $^{\S}$ and New York City, Pregnancy Risk Assessment Monitoring System, 2009-2011

\begin{tabular}{|c|c|c|c|c|c|}
\hline \multirow{2}{*}{\multicolumn{2}{|c|}{ Maternity care practices experienced ${ }^{*}$}} & \multicolumn{4}{|c|}{$\operatorname{aPR}(95 \% \mathrm{Cl})^{9}$} \\
\hline & & \multicolumn{2}{|c|}{ Any breastfeeding } & \multicolumn{2}{|c|}{ Exclusive breastfeeding } \\
\hline No. & Prevalence (\%) & $\geq 4$ weeks & $\geq 8$ weeks & $\geq 4$ weeks & $\geq 8$ weeks \\
\hline 0 & 9.6 & 1.00 Ref. & 1.00 Ref. & 1.00 Ref. & 1.00 Ref. \\
\hline 1 & 18.3 & $1.00(0.59-1.68)$ & $1.54(0.62-3.82)$ & $0.99(0.47-2.09)$ & $0.85(0.37-1.98)$ \\
\hline 2 & 28.1 & $1.53(0.97-2.41)$ & $2.47(1.04-5.85)$ & $1.13(0.56-2.30)$ & $0.96(0.43-2.14)$ \\
\hline 3 & 22.4 & $1.73(1.10-2.72)$ & $3.24(1.38-7.57)$ & $1.97(1.01-3.85)$ & $1.86(0.87-3.97)$ \\
\hline 4 & 14.3 & $1.66(1.05-2.64)$ & $2.97(1.26-7.03)$ & $2.43(1.25-4.72)$ & $1.69(0.78-3.68)$ \\
\hline 5 & 7.4 & $1.82(1.13-2.92)$ & $3.68(1.55-8.73)$ & $2.49(1.24-4.97)$ & $2.23(1.01-4.92)$ \\
\hline $\mathrm{P}$-value for linear trend & & $<0.05$ & $<0.05$ & $<0.05$ & $<0.05$ \\
\hline
\end{tabular}

Abbreviations: $\mathrm{aPR}=$ adjusted prevalence ratios; $\mathrm{Cl}=$ confidence interval; Ref. $=$ reference value.

* Maternity care practices are defined as practices that correspond with a step in the Ten Steps to Successful Breastfeeding as well as the practice of not providing a hospital gift pack that contains infant formula. The significant maternity care practices in this study and included in this table, are breastfeeding in the first hour after delivery, feeding infant only breast milk at the hospital, being told by hospital staff to breastfeed infant on demand, not using a pacifier in the hospital, and not receiving a hospital gift pack that contained formula.

† For this report, adolescents are defined as persons aged 12-19 years.

$\S$ Alaska, Arkansas, Colorado, Maine, Minnesota, New Jersey, New York, Oregon, Texas, Vermont.

ף Boldface indicates a statistically significant result.

proportion make their decision to breastfeed late in pregnancy or during the delivery hospitalization (8). Although breastfeeding is sometimes described as natural, it is also a learned behavior, and many mothers, including adolescent mothers, often need assistance to meet their infant feeding goals. To breastfeed, a mother must establish lactation, the physiologic process of producing breast milk, which occurs through a supply and demand relationship. Breastfeeding initiation and the early biologic processes that establish lactation typically occur during the intrapartum hospital stay (9). Approximately $99 \%$ of U.S. births occur in hospitals (10). Thus, the intrapartum hospital stay provides a critical opportunity to offer adolescent mothers accurate information about breastfeeding to enable them to make an informed decision about how they 


\section{Summary}

What is already known on this topic?

Breast milk is the optimal source of nutrition for most infants and confers many health and economic benefits to both mother and child. Maternity care practices that occur during the intrapartum hospital stay influence the initiation and duration of any and exclusive breastfeeding.

What is added by this report?

Among adolescent mothers (for this report, adolescents are defined as persons aged 12-19 years) who initiated breastfeeding, the self-reported prevalence of experiencing breastfeedingsupportive maternity care practices ranged from $29.2 \%$ (not receiving a hospital gift pack that contained formula) to $95.4 \%$ (receiving information about breastfeeding from hospital staff). Among the maternity care practices with a significant independent association with any and exclusive breastfeeding for $\geq 4$ weeks and $\geq 8$ weeks, there was a positive dose-response relationship between the number of practices experienced by adolescent mothers and their breastfeeding outcomes.

What are the implications for public health practice?

The intrapartum period is a critical time to reach adolescent mothers with evidence-based maternity practices. Receiving evidence-based breastfeeding-supportive maternity care can increase the prevalence of any and exclusive breastfeeding among adolescent mothers.

will feed their infant, and to provide assistance with breastfeeding, all of which contribute to the knowledge, skills, and confidence adolescent mothers need to continue breastfeeding after hospital discharge.

The Surgeon General's Call to Action to Support Breastfeeding includes a number of recommended actions that can be taken to improve support for breastfeeding mothers. One of the action steps calls on health care clinicians to ensure that maternity practices throughout the United States are fully supportive of breastfeeding (3). This study demonstrates that adolescent mothers are not receiving care that is consistent with evidence-based guidelines. The Ten Steps are evidence-based maternity practices that support breastfeeding and that are meant to be delivered to mothers as a comprehensive package $(3,5)$. The findings of this study indicate that it is important for hospitals to ensure that all mothers, including adolescent mothers, experience practices that are aligned with the Ten Steps, and that they do not receive hospital gift packs that contain formula as part of routine maternity care, to help them meet their personal infant feeding goals.

This findings in this report are subject to at least three limitations. First, PRAMS data are self-reported and might be subject to recall bias. Second, the maternity practices module was asked only of mothers who initiated breastfeeding; thus, it was not possible to assess how the practices influenced breastfeeding initiation. In addition, the inclusion of only mothers who initiated breastfeeding might explain why the steps that are typically associated with breastfeeding initiation were not significantly associated with duration or exclusivity of breastfeeding. Finally, this study included only those adolescent mothers with healthy newborns; hence, the results might not be generalizable to more vulnerable infants, such as those who are born preterm, and who might be most in need of the health protections breast milk provides.

Breastfeeding confers numerous health advantages that are particularly important for adolescent mothers and their children, who constitute a vulnerable group, both in terms of being at risk for suboptimal breastfeeding and related health effects (1). Ensuring that adolescent mothers (and all mothers) receive optimal, evidenced-based maternity care, can improve breastfeeding duration and exclusivity rates, ultimately leading to improved maternal and child health outcomes.

\section{Acknowledgments}

Brian Morrow, Denise D'Angelo, Division of Reproductive Health, National Center for Chronic Disease Prevention and Health Promotion, CDC; Qun Zheng, Kathy Perham-Hester, Mary McGehee, Alyson Shupe, Jennifer Morin, George Yocher, Kelsi E. Williams, Chinelo Ogbuanu, Jane Awakuni, Theresa Sandidge, Sarah Mauch, Amy Zapata, Tom Patenaude, Diana Cheng, Emily Lu, Patricia McKane, Judy Punyko, Brenda Hughes, Venkata Garikapaty, JoAnn Dotson, Brenda Coufall, David J. Laflamme, Ingrid M. Morton, Eirian Coronado, Anne Radigan-Garcia, Candace Mulready-Ward, Kathleen Jones-Vessey, Sandra Anseth, Connie Geidenberger, Alicia Lincoln, Kenneth Rosenberg, Tony Norwood, Sam Viner-Brown, Mike Smith, Tanya Guthrie, Ramona Lainhart, Laurie Baksh, Peggy Brozicevic, Christopher Hill, Linda Lohdefinck, Melissa Baker, Katherine Kvale, Amy Spieker, PRAMS Working Group, CDC; CDC PRAMS Team, Applied Sciences Branch, Division of Reproductive Health, CDC.

\footnotetext{
${ }^{1}$ Epidemic Intelligence Service, CDC; ${ }^{2}$ Division of Reproductive Health National Center for Chronic Disease Prevention and Health Promotion, CDC.

Corresponding author: Oluwatosin Olaiya, OOlaiya@cdc.gov, 404-639-2599.
}

\section{References}

1. American Academy of Pediatrics Section on Breastfeeding. Breastfeeding and the use of human milk. Pediatrics 2012;129:e827-41. http://dx.doi. org/10.1542/peds.2011-3552.

2. World Health Organization. Protecting, promoting and supporting breastfeeding: the special role of maternity services. Geneva, Switzerland: World Health Organization; 1989. http://apps.who.int/iris/handle/10665/39679.

3. Office of the Surgeon General; CDC; Office on Women's Health. The Surgeon General's Call to Action to Support Breastfeeding. Rockville, MD: Office of the Surgeon General; 2011. http://www.surgeongeneral. gov/library/calls/breastfeeding.

4. DiGirolamo AM, Grummer-Strawn LM, Fein SB. Effect of maternity-care practices on breastfeeding. Pediatrics 2008;122(Suppl 2):S43-9. http:// dx.doi.org/10.1542/peds.2008-1315e. 
5. Murray EK, Ricketts S, Dellaport J. Hospital practices that increase breastfeeding duration: results from a population-based study. Birth 2007;34:202-11. http://dx.doi.org/10.1111/j.1523-536X.2007.00172.x.

6. Bieler GS, Brown GG, Williams RL, Brogan DJ. Estimating model-adjusted risks, risk differences, and risk ratios from complex survey data. Am J Epidemiol 2010;171:618-23. http://dx.doi.org/10.1093/aje/kwp440.

7. Ip S, Chung M, Raman G, et al. Breastfeeding and maternal and infant health outcomes in developed countries. Evid Repr Technol Assess (Full Rep) 2007;153.
8. Sipsma HL, Divney AA, Magriples U, Hansen N, Gordon D, Kershaw T. Breastfeeding intentions among pregnant adolescents and young adults and their partners. Breastfeed Med 2013;8:374-80.

9. Shealy KR, Li R, Benton-Davis S, Grummer-Strawn LM. The CDC Guide to Breastfeeding Interventions Atlanta, GA: US Department of Health and Human Services, CDC; 2005. http://www.cdc.gov/ breastfeeding/pdf/breastfeeding_interventions.pdf.

10. MacDorman MF, Matthews TJ, Declercq E. Trends in out-of-hospital births in the United States, 1990-2012. NCHS Data Brief 2014; 144:1-8. 